\title{
Secondary transport as an efficient membrane transport mechanism for plant secondary metabolites
}

\author{
Kazufumi Yazaki · Akifumi Sugiyama • \\ Masahiko Morita $\cdot$ Nobukazu Shitan
}

Received: 18 October 2007 / Accepted: 2 November 2007/Published online: 24 November 2007

(C) The Author(s) 2007

\begin{abstract}
Plants produce a large number of secondary metabolites, such as alkaloids, terpenoids, and phenolic compounds. Secondary metabolites have various functions including protection against pathogens and UV light in plants, and have been used as natural medicines for humans utilizing their diverse biological activities. Many of these natural compounds are accumulated in a particular compartment such as vacuoles, and some are even translocated from source cells to sink organs via long distance transport. Both primary and secondary transporters are involved in such compartmentation and translocation, and many transporter genes, especially genes belonging to the multidrug and toxin extrusion type transporter family, which consists of 56 members in Arabidopsis, have been identified as responsible for the membrane transport of secondary metabolites. Better understandings of these transporters as well as the biosynthetic genes of secondary metabolites will be important for metabolic engineering aiming to increase the production of commercially valuable secondary metabolites in plant cells.
\end{abstract}

K. Yazaki $(\bowtie) \cdot$ A. Sugiyama · M. Morita $\cdot$ N. Shitan Laboratory of Plant Gene Expression, Research Institute for Sustainable Humanosphere, Kyoto University, Gokasho, Uji 611-0011, Japan e-mail: yazaki@rish.kyoto-u.ac.jp
Keywords ABC protein - MATE .

Membrane transport - Secondary transport .

Translocation

\begin{abstract}
Abbreviations
ABC ATP-binding cassette

MATE Multidrug and toxin extrusion
\end{abstract}

\section{Introduction}

Plants produce a large number of low-molecularweight organic compounds that appear to have little function in their growth and development. These compounds, designated as secondary metabolites, differ from primary metabolites, such as carbohydrates, amino acids, and nucleotides that have basic functions to maintain the life cycle, cell division and acquiring energy, in their restricted distribution in the plant kingdom, i.e. occurring in some limited plant families or even specific species. Many secondary metabolites have diverse biological activities, and function in defense responses against pathogens and herbivores and in protecting plants from damage by UV light. Some secondary metabolites also have pharmacological importance as natural medicines for humans, and intensive studies have been carried out to characterize the nature of secondary metabolites from the viewpoints of their biological activities, chemical structures, biosynthesis, and their functions 
in plants as well as their clinical usage (Croteau et al. 2000). Secondary metabolites are often found to be accumulated in particular tissues at a high concentration. This accumulation in such appropriate compartments should be regulated in a highly sophisticated manner, because some secondary metabolites are even toxic to plants themselves if they are mislocalized.

Secondary metabolites are transported intercellularly, intracellularly, and in an intratissue fashion. As an example of intratissue movement of secondary metabolites, nicotine is well characterized for its unique translocation. Nicotine is an alkaloid specifically found in plants belonging to the Solanaceae, and is synthesized in the roots and then translocated to the leaves, where it functions as an insect neurotoxin to protect the plants (Hashimoto and Yamada 2003). For such translocation, at least three membrane transport events may be involved, i.e. export from the plasma membrane in root cells, import at the plasma membrane in leaf cells, and additional transport into the vacuoles in leaf cells (Fig. 1). In plant cells, vacuoles, which occupy as much as $90 \%$ of the cells volume, play a central role in the accumulation of secondary metabolites such as alkaloids and flavonoids, and a large number of transporters, channels and pumps reside in the vacuolar membrane (tonoplast) (for review see
Martinoia et al. 2007). Intercellular and intracellular transport activities are mediated by specific transporters in most cases. Transporters mediating active transport can be roughly divided into two groups based on their energy source to generate movement across the membrane; those for primary transport, which use the hydrolysis of ATP such as ATPbinding cassette $(\mathrm{ABC})$ transporters, and others for secondary transport, which use electrochemical gradients of protons or sodium ions that are created by proton pumps, i.e. P-type ATPases in the plasma membrane and V-type ATPases as well as pyrophosphatase in the tonoplast (Gaxiola et al. 2007). As several $\mathrm{ABC}$ transporters that mediate the transport of secondary metabolites are summarized in recent reviews (Yazaki 2005, 2006; Rea 2007), we provide in this review article an overview of secondary transporters responsible for the transport of plant natural products.

\section{Transporters of plant secondary metabolites}

Secondary metabolites are classified into several groups by their chemical structure and the biosynthetic routes providing these natural compounds. In the first half of this article, the transport of each class is summarized.
Fig. 1 Model of nicotine translocation in Nicotiana species. Nicotine biosynthesis is induced in root cells, via insect attack, wounding, and jasmonate treatment to the leaves. After biosynthesis nicotine is translocated to the leaves via the xylem, and is accumulated in the vacuoles of leaves to function as a defensive toxin against insects and herbivores

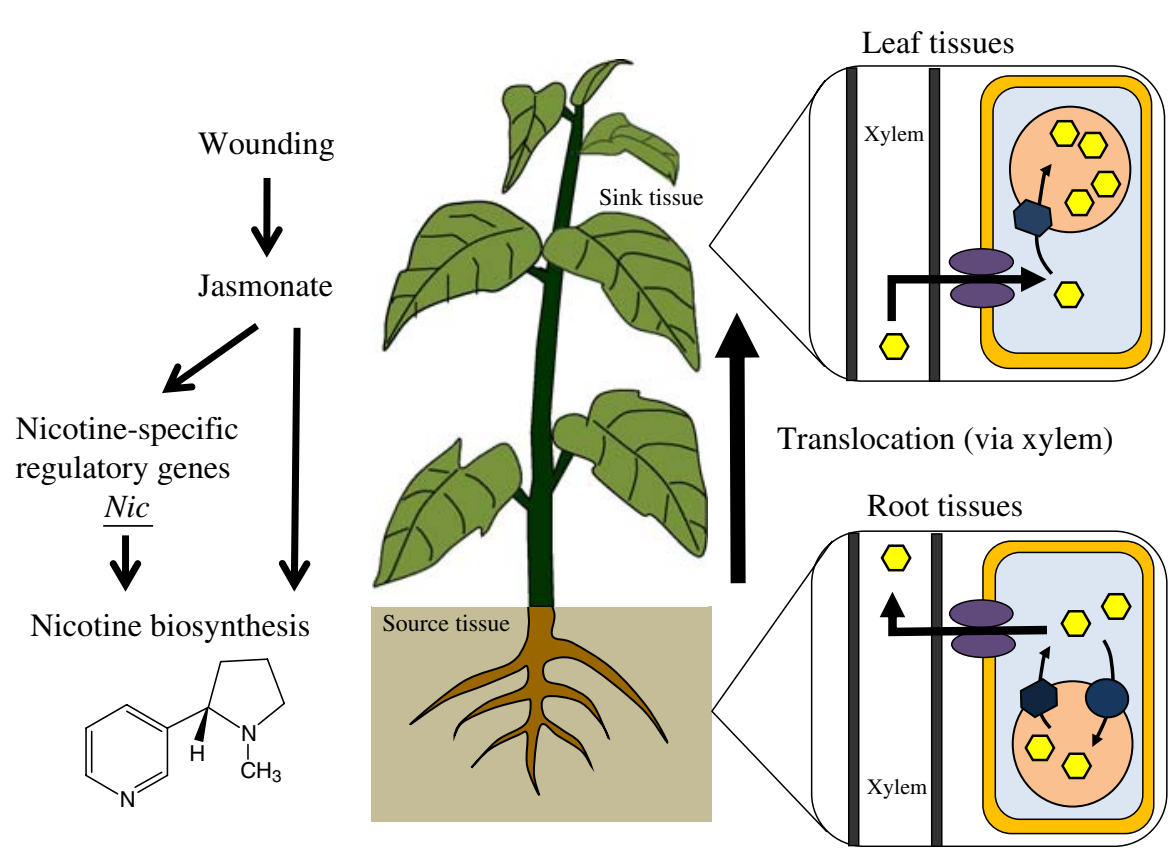


Transporters for alkaloids

Alkaloids are nitrogen-containing low-molecularweight organic compounds, which are mostly aromatic metabolites. To date approximately 12,000 alkaloid compounds have been found in about one-fifth of plant species (Croteau et al. 2000; Hashimoto and Yamada 2003), and which have a wide variety of chemical structures and biological activities. Because of their bioactive properties, alkaloids are often sequestered in the vacuoles of plant cells to avoid toxic effects. Many studies have been thus far carried out to characterize the mechanism of vacuolar accumulation of alkaloids using cell cultures, protoplasts, and isolated native vacuoles. An early study with isolated vacuoles of Catharanthus roseus suggested the involvement of a specific protonantiporter for various endogenous alkaloids, including vindoline and ajmaline (Deus-Neumann and Zenk 1984). These authors further demonstrated that an energy-dependent proton-antiporter mediated the uptake of the intermediates of the indole alkaloids, reticuline and scoulerine, into the vacuoles of Fumaria capreolata, and excluded the involvement of an ion-trap mechanism in the vacuolar uptake of these alkaloids (DeusNeumann and Zenk 1986). Another biochemical characterization with $C$. roseus protoplasts showed an energy-dependent transporter, which is specific for its endogenous alkaloid, vindoline, although the ion-trap mechanism also partly contributed to the vacuolar uptake of these endogenous alkaloids (McCaskill et al. 1988). These results demonstrate that the uptake of alkaloids into vacuoles is not as simple as previously thought (Neumann et al. 1983; Matile 1984), i.e. both alkaloidspecific transporters and an ion-trap mechanism are probably mediating these processes. Another mechanism includes the chemical modification of alkaloid molecules inside the vacuoles, for example ajmalicine is converted to serpentine by a vacuolar-localized basic peroxidase in C. roseus cells (Blom et al. 1991). However, despite many biochemical studies carried out on vacuolar alkaloid transport, no gene responsible for the membrane transport of these indole alkaloids has been identified, to our knowledge, so far.

A yellow isoquinoline alkaloid, berberine, is widely used as an antibacterial and antimalarial drug as well as bitter stomachic in many countries (Yamamoto et al. 1993; Iwasa et al. 1998). Berberine occurs in many plant species belonging to various families such as Berberidaceae, Menispermaceae,
Mognoliaceae, Paparerareae, Ranunculaceae, and Rutaceae, out of which cultured cells of Coptis japonica (Ranunculaceae) and Thalictrum minus (Ranunculaceae) have been used to study the transport mechanisms of this alkaloid. These are appropriate models to characterize the transport of berberine, i.e. C. japonica cells accumulate berberine exclusively in the vacuoles and they also actively uptake berberine exogenously added to the medium (Sato et al. 1990, 1993, 1994), whereas T. minus secretes most of the berberine biosynthesized in the cells into the medium (Nakagawa et al. 1984). The characterization of the cellular uptake of berberine into cultured cells of C. japonica suggested the involvement of an ABCtype transporter (Sakai et al. 2002) and accordingly the gene for the berberine importer functioning at the plasma membrane was identified as being an ABCBtype ABC transporter, CjMDR1 (Shitan et al. 2003), whose name was derived from the conventional name for multidrug resistance, although such broad substrate specificity was not observed in this plant $A B C$ protein. In contrast, the characteristics of berberine transport in the vacuolar membrane met the criteria for a proton-antiporter, because inhibition of V-type ATPase by bafilomycin A1 and the disruption of delta $\mathrm{pH}$ across the vacuolar membrane by ammonium ions clearly inhibited berberine uptake, while sodium ortho-vanadate, a general inhibitor of $\mathrm{ABC}$ proteins, did not inhibit the uptake (Otani et al. 2005). The iontrap mechanism was also excluded from the berberine accumulation mechanism in the $C$. japonica vacuoles by the analysis of membrane vesicles (Otani et al. 2005). It is noteworthy that two different types of transport by an ABC transporter and a protonantiporter mediate the membrane transport of berberine in one cell. However, no candidate gene for the proton-berberine antiporter has been identified thus far. For the efflux mechanism of berberine in T. minus cells, we have also demonstrated the involvement of an ABC transporter (Terasaka et al. 2003), and have identified several candidate genes (our unpublished results).

Nicotine is the most abundant alkaloid in tobacco leaves. It is highly toxic to insects and moderately to plants cells and therefore is accumulated in the leaf vacuoles (Fig. 1). We have recently identified some strong candidates for nicotine transporter genes of tobacco by cDNA-AFLP (amplified fragment length polymorphisms) (Goossens et al. 2003), and these 
genes are classified into the multidrug and toxin extrusion (MATE) family transporters (our unpublished results), which are discussed later in further detail.

Transporters for phenolic compounds

Plant phenols are represented by their aromatic ring structures containing more than one phenol residue. These compounds can be classified into simple phenolic compounds, including phenylpropanes $\left(\mathrm{C}_{6}-\mathrm{C}_{3}\right)$ and $\mathrm{C}_{6}-\mathrm{C}_{1}$ compounds, stylbenes, lignans, xanthenes, flavonoids, and tannins as polymers of polyphenols that are classified into two types, i.e., hydrolyzable or condensed tannins. From the viewpoint of transport, flavonoids have been intensively studied. Flavonoids represent one of the largest classes of plant phenolics consisting of more than 7,000 compounds, which are involved in plant pathogen interactions and UV light protection, and also in the variation of flower color. Most flavonoids mainly exist as their glycosylated form in planta, and glycosylation is thought to be a prerequisite for the transport of flavonoid molecules into vacuoles. For example in barley, an endogenous flavonoid glucoside, isovitexin (apigenin 6- $C$-glucoside), is transported into the vacuoles of barley via an electrochemical-gradient dependent transport mechanism (secondary transport), which showed clear specificity for apigenin derivatives (Klein et al. 1996). In contrast, an abiotic glucoside, hydroxyprimisulfuron-glucoside, was transported into barley vacuoles via a primary transporter. These biochemical characterizations suggest that vacuolar transporters of barley distinguish endogenous glucosides from exogenous glucosides. Moreover, even for the same compound, saponarin (apigenin 6- $\mathrm{C}$-glucosyl-7- $\mathrm{O}$-glucoside), Klein and co-workers reported that this major barley flavonoid glucoside is transported by a proton-antiporter in the vacuolar membrane of barley to be accumulated, while it is recognized by a primary transporter in Arabidopsis, which does not produce this flavonoid glucoside, indicative that saponarin is recognized as a xenobiotic (Frangne et al. 2002).

The barley ant 310 mutant has a mutation in the chalcone isomerase gene and therefore contains less than 5\% of the flavonoids of wild-type plants (Reuber et al. 1996). It has been shown very recently that isolated vacuoles of ant310 mutants exhibited strongly reduced transport activity for saponarin and isovitexin (Marinova et al. 2007a); however, the transport activity was restored by the incubation with their flavonoid precursor, naringenin, after which the saponarin contents increased up to wild-type level. These results demonstrate that the abilities of biosynthesis and transport of flavonoids are interconnected. If this correlation is not limited to barley, bioinformatics analysis on the transcriptomics linkage map will provide possible transporter genes for endogenous secondary metabolites.

Among various flavonoid glucosides, anthocyanins, which are colored flavonoids responsible for most of the red, pink, purple, and blue color in flowers according to the in vivo state and derivatization patterns, are one of the most well-studied phenolic compounds. They are accumulated in the vacuoles of various plants and act as an attractant for pollinators and protectant from UV light. The uptake of anthocyanins into the vacuoles was reported by several laboratories with various plant species, but according to systems used, the mechanism may differ, i.e. either by primary or secondary transport. The involvement of a primary transporter that transports anthocyanins in the vacuolar membrane was first suggested in the bronze-2 (bz-2) mutant of maize (Marrs et al. 1995). The $b z-2$ mutant is defective in glutathione $S$-transferase and failed to accumulate anthocyanin in the vacuoles. Because glutathione conjugates are recognized as common substrates for multidrug resistance associated protein (MRP/ABCC)-type ABC transporters, the involvement of an ABCC-type $\mathrm{ABC}$ transporter has been presumed in the vacuolar transport of anthocyanins. This idea was later strongly supported by the identification of ZmMrp3, a tonoplast localized ABCC-type transporter gene, and its antisense suppression resulted in a reduced level of anthocyanin accumulation (Goodman et al. 2004). In contrast, transport studies with Arabidopsis revealed that a secondary transporter mediated the uptake of anthocyanins into the vacuoles, and this transporter belongs to the MATE family (see the section below for details).

Legume plants synthesize flavonoid aglycons, and secrete some of them into the root exudates as signal molecules for rhizobia leading to the establishment of the symbiotic nitrogen fixation (Smit et al. 1992). 
Recently, we have investigated the transport mechanism of flavonoid secretion from the root using soybean and its signal flavonoid genistein. Membrane vesicle transport assays demonstrated that an ABCtype transporter could mediate the secretion of genistein from soybean roots (Sugiyama et al. 2007), although there still remains the possibility for other legume plants that secondary transporters will be responsible for the secretion of their signal molecules.

Transport of phenylpropanoid glucosides was also characterized biochemically. Quinone compounds may be classified into phenolic compounds due to the relevance of their oxidation state, while biosynthetic routes of naturally occurring quinines are rather specialized for some quinones. Accumulation and related membrane transport are not well elucidated for quinines, but among benzo-, naphtho-, and anthraquinone compounds, the secretion of lipophilic red naphthoquinone shikonin derivatives has been characterized, where a vesicle trafficking-like mechanism was reported (Kunst and Samuels 2003; Yazaki 2005). However, protein members involved in the extracellular accumulation of shikonin have not yet been identified.

\section{Transporters for terpenoids}

Terpenoids constitute the largest class of secondary metabolites with more than 25,000 compounds (Croteau et al. 2000). Terpenoids are formed from prenyl diphosphates of different chain length, which are provided by the consecutive elongation of five-carbon isoprene units, such as dimethylallyl diphosphate and isopentenyl diphosphate, forming hemiterpenes (one $\mathrm{C}_{5}$ unit), monoterpenes (two $\mathrm{C}_{5}$ units), sesquiterpenes (three $\mathrm{C}_{5}$ units), diterpenes (four $\mathrm{C}_{5}$ units), sesterterpenes (five $\mathrm{C}_{5}$ units), triterpenes (six $\mathrm{C}_{5}$ units), tetraterpenes (eight $\mathrm{C}_{5}$ units), and further polymers. Although the biosynthetic pathways and physiological roles of terpenoids have been actively characterized, there has been no report on transporter proteins for terpenoids so far, except for a pleiotropic drug resistance (PDR/ABCG)-type ABC transporter of Nicotiana plumbaginifolia (NtPDR1) that is involved in the secretion of an endogenous antifungal diterpene, sclareol, onto its leaf surface (Jasinski et al. 2001). The smallest terpenoid isoprene is vigorously emitted from the leaves of many plant species, which contributes to the thermotolerance in plants (Behnke et al. 2007; Loivamaki et al. 2007; Sasaki et al. 2007), but it is thought that no transporters are involved in this massive emission from leaf cells to the air (Niinemets et al. 2004). Studies on transporter proteins for mono- or sesquiterpenoid will provide a breakthrough in this research field.

\section{Transporters for other metabolites}

Plant sucrose transporters are proton-symporters, and some of them are reported to mediate the transport of various compounds other than sucrose. For example, PmSUC2 of Plantago major and AtSUC5 transported biotin (vitamin $\mathrm{H}$ ) when expressed in yeast (Ludwig et al. 2000), although biotin is not a plant secondary metabolite. The expression of AtSUC2 in Xenopus oocytes suggested the ability of this transporter to uptake various glucosides including arbutin and salicin (Chandran et al. 2003). The ability of sucrose transporters to mediate the uptake of these structurally divergent metabolites is indicative that this transporter family may contribute to facilitate the movement of various secondary metabolites across membranes in planta.

Urea is a nitrogen-containing metabolite in plants. It was reported that an Arabidopsis transporter belonging to the sodium solute symporters family, AtDUR3, mediates the uptake of urea when expressed in Xenopus oocytes and yeast (Liu et al. 2003), while several plant aquaporins were also reported to transport urea in a channel-like manner (Kojima et al. 2006). The in planta function of AtDUR3 was recently reported as a high-affinity urea transporter involved in the uptake of urea from soil, which was demonstrated by expression analyses and transport studies using atdur3 mutants (Kojima et al. 2007).

\section{MATE transporters, an emerging transporter family mediating various cellular processes}

The MATE family was originally found in prokaryotes and their function as multiple drug efflux carrier was studied in detail. However, orthologues in higher organisms have been characterized only in recent years, and some plant MATE members showed particular physiological functions with strict 
specificity to transport particular substrates. In the last half of this article, we focus on the MATE members to summarize their functions.

MATE transporters in bacteria and animals

MATE transporters consist of 400-700 amino acids with 9-12 transmembrane $\alpha$-helices (Fig. 2), but no apparent consensus sequence has been identified unlike $\mathrm{ABC}$ transporters that contain unique $\mathrm{ABC}$ signature(s), although three amino acids conserved in one cluster of the MATE family were reported to be essential for the antiport function of bacterial MATEs (Otsuka et al. 2005b). The first MATE transporter was identified from the screening of Vibrio parahaemolyticus genes that confer resistance for norfloxacin, a widely used antimicrobial compound (Morita et al. 1998). The identified gene product was named NorM and reported to function as a sodium-multidrug antiporter that transport various structurally unrelated compounds (Morita et al. 2000). To data, MATE transporters have been reported in all living organisms characterized, and the functions of some members are being elucidated (Omote et al. 2006). The human genome contains two genes (MATE1 and MATE2) encoding MATE transporters. MATE1 is highly expressed in the liver and kidney, and when expressed in HEK293 cells it transported tetraethylammonium, a typical cationic substrate of this family, and 1-methyl-4-phenylpyridinium in a proton-coupled manner (Otsuka et al. 2005a), and MATE2 is also reported to transport various organic cations (Masuda et al. 2006). These results, along with the report of a mouse MATE1 transporter (Hiasa et al. 2006), suggest that mammalian MATE transporters function in the excretion of toxic organic cations from renal tubular cells and hepatocytes.

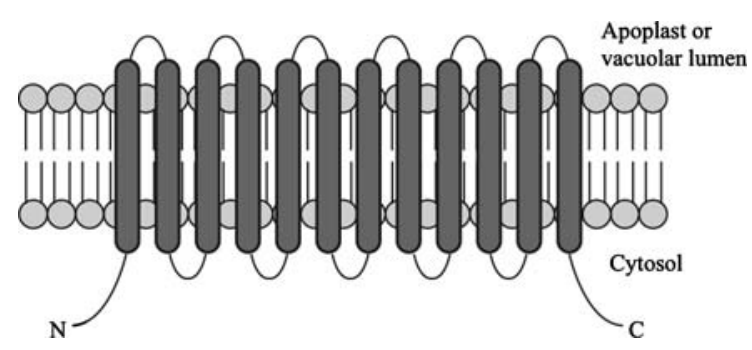

Fig. 2 Putative secondary structure of MATE transporters
MATE transporters in plants

Arabidopsis contains 56 MATE transporter genes in its genome (Fig. 3). This family size is remarkably large compared to the human counterpart (only two members), although their functions have been only elucidated for some members in recent years. The first report on a plant MATE transporters concerned AtALF5, which was identified from a mutant defective in lateral root formation (aberrant lateral root formation) (Diener et al. 2001). Heterologous expression of AtALF5 in yeast conferred resistance to tetramethylammonium, suggesting its function in detoxification as an efflux transporter for xenobiotics. Another MATE member of Arabidopsis, AtDTX1, was identified from the functional screening of a cDNA complementing the growth of a norfloxacinhypersensitive Escherichia coli mutant ( $\mathrm{Li}$ et al. 2002). When expressed in E. coli, AtDTX1 conferred multiple tolerance to berberine and cadmium in addition to norfloxacin, which suggests that AtDTX1 is also an efflux carrier for multidrug resistance, although the tested compounds are still limited in number. Recently a unique MATE transporter has been identified by the positional cloning of an Arabidopsis enhanced disease susceptibility (eds) mutant that accumulated little salicylic acid, a second messenger in plant-pathogen interactions and showed hypersensitivity to pathogens (Nawrath et al. 2002). The expression of AtEDS5 was induced by pathogen attack and UV-C treatment. Functional analyses have not been carried out with this MATE transporter, but organic molecules involved in the signal transduction cascade and precursors of salicylic acids are suggested as possible substrates.

Arabidopsis contains flavonoid pigments in the mature seed coat (testa), where proanthocyanidins accumulate exclusively in the endothelium layer (Devic et al. 1999). Several Arabidopsis transparent testa $(t t)$ mutants have been isolated via screening for altered pigmentation in the seed coat, and the responsible genes have been identified as being for the biosynthetic enzymes of flavonoids (Lepiniec et al. 2006), while AtTT12, identified as a T-DNA tag line, was found to encode a MATE-type transporter (Debeaujon et al. 2001). AtTT12 was presumed to be a vacuolar transporter for flavonoids in the seed coat, but its function remained unknown until Klein and co-workers in a collaboration with Debeaujon's group 


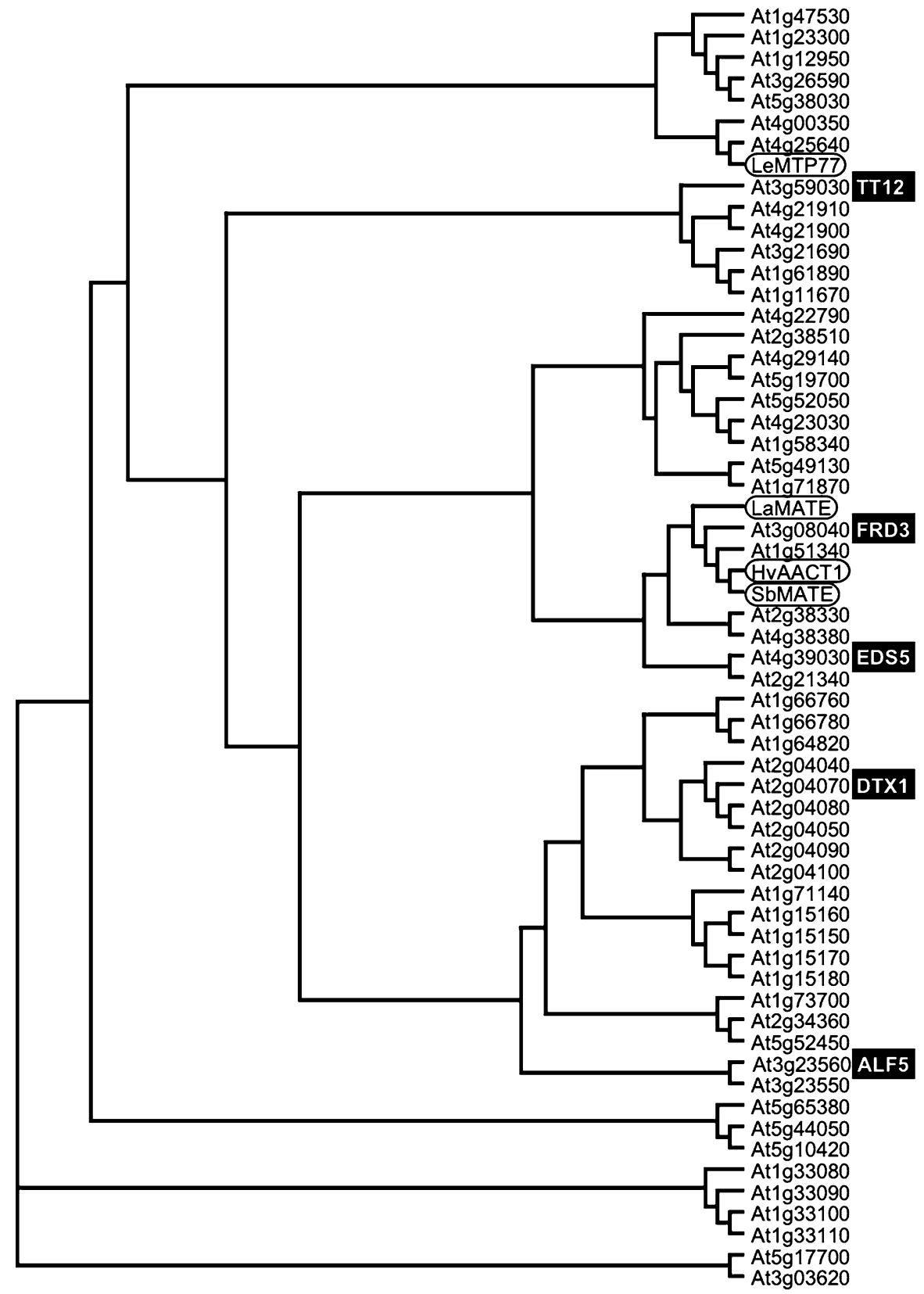

Fig. 3 Phylogenetic relationship of plant MATE family members. The amino acid sequences of MATE members were aligned using ClustalW and subjected to phylogenetic analysis provided by EMBL-EBI. Arabidopsis MATE members are indicated as Arabidopsis Genome Initiative (AGI) codes, and

have recently reported the precise functions of AtTT12 (Marinova et al. 2007b). It was shown that the AtTT12 gene was expressed specifically in cells reported names are highlighted in white. MATE members of other plant species are shown in circles. Accession number are as follows; LeMTP77 (tomato), AY348872; LaMATE (Lupinus albus), AY631874; HvAACT1 (barley), AB302223; SbMATE (Sorghum bicolor), EF611342

synthesizing proanthocyanidins, and the AtTT12 polypeptide localized to the vacuolar membrane. They also demonstrated that yeast microsome vesicles 
expressing AtTT12 mediated the membrane transport of cyanidin-3-O-glucoside but not of procyanidin dimers, quercetin-3-O-rhamnoside, quercetin-3-Oglucoside, or catechin-3-O-glucoside, while catechin3-O-glucoside strongly inhibited the transport of cyanidin-3-O-glucoside in a dose-dependent manner. From these results, Klein and co-authors concluded that AtTT12 is a tonoplast proton-antiporter in proanthocyanidins-synthesizing cells of the seed coat, which mediates the transport of anthocyanin. A similar MATE transporter (MTP77) of tomato has also been reported as a putative anthocyanin transporter at the vacuole (Mathews et al. 2003), but the biochemical function as a transporter is still to be characterized.

Another Arabidopsis MATE transporter was identified from the screening of mutants that constitutively express iron-deficient inducible genes under ironsufficient conditions (Rogers and Guerinot 2002). The MATE transporter named AtFRD3 after ferric reductase defective was expressed predominantly in roots and was necessary for correct iron distribution throughout the plant (Green and Rogers 2004). Further functional analysis of AtFRD3 in Xenopus oocytes has shown recently that AtFRD3 mediates the efflux of citrate to the apoplast and is not directly involved in iron transport (Durrett et al. 2007). Together with the localization of this transporter in the root vasculature, Durrett and colleagues suggested that AtFRD3 effluxed citrate into the root vasculature, which facilitated the translocation of iron-citrate complexes to the leaves. A white lupin homologue of AtFRD3, LaMATE, was reportedly upregulated in phosphorus deficiency conditions and under aluminum stress as well (Uhde-Stone et al. 2005). In fact, RNAi-silencing of LAMATE exhibited the reduction of growth under phosphorous deficiency, but its functions regarding transport of particular substances are still unknown.

\section{MATE transporters and aluminum resistance}

Aluminum is the most abundant metal in the earth's crust. Although aluminum in the form of aluminosilicates is harmless to plants, aluminum solubilized in the form of $\mathrm{Al}^{3+}$ in acid soil is highly toxic to plants producing strong growth defect, which is most

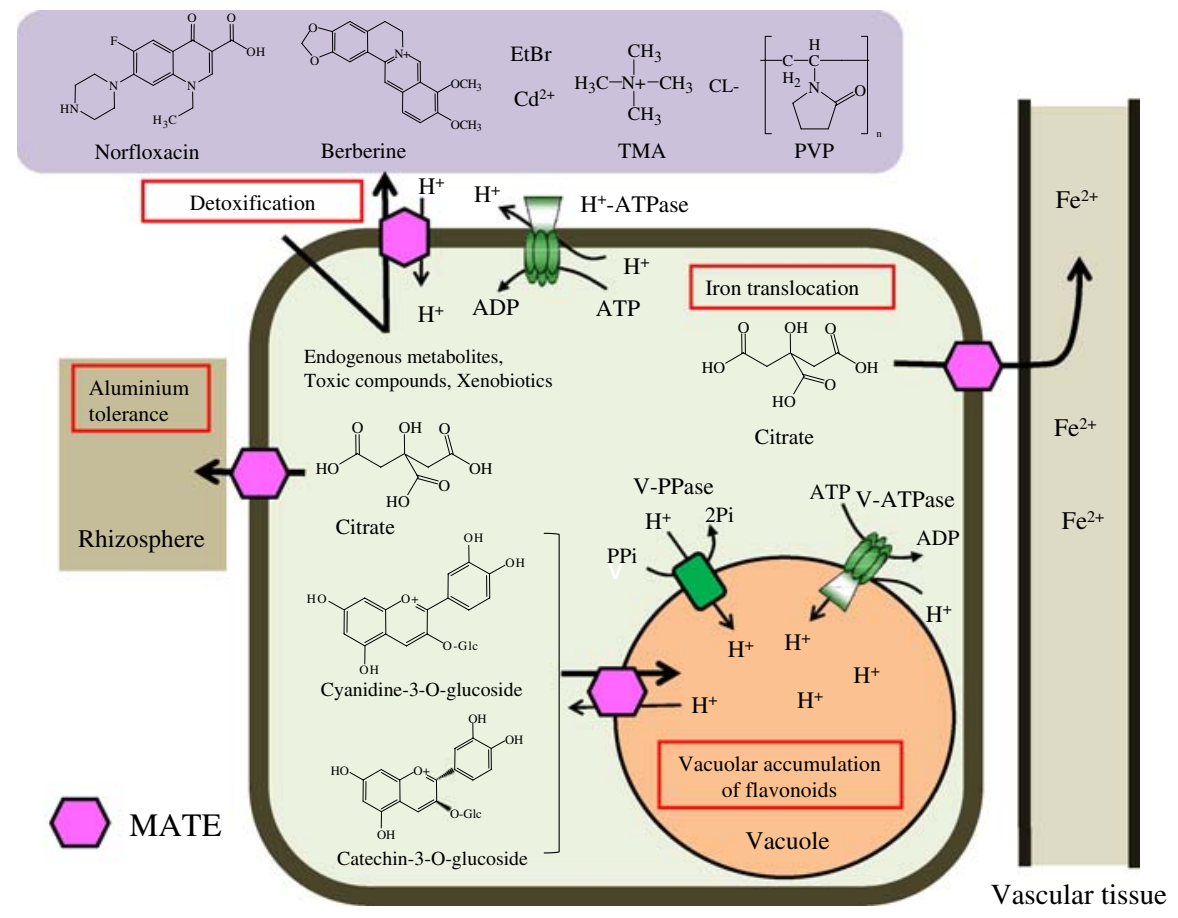

Fig. 4 A model of the physiological functions and putative substrates of MATE transporters in plants 
prominent as rapid inhibition of root elongation (Ma and Furukawa 2003). A well-known mechanism of aluminum resistance in plants is the secretion of organic anions such as citrate, oxalate, and malate from the roots (Ma et al. 2001; Kochian et al. 2005). As an experimental proof, the over-expression of AtFRD3, which enhanced exudation of citrate and malate from roots of transgenic Arabidopsis, led to the higher tolerance to aluminum (Durrett et al. 2007). In accordance with this result, several MATE transporters conferring aluminum tolerance have been reported recently. In barley high-resolution mapping of the Alp locus that conditions aluminum tolerance, a gene encoding MATE transporter (HvMATE) was identified as a candidate controlling aluminum resistance (Wang et al. 2007). This barley MATE transporter gene is essentially the same as $H v A A C T 1$, identified from a fine mapping and microarray analysis by
Furukawa and co-workers (Furukawa et al. 2007). When expressed in Xenopus oocytes, HvAACT1 protein mediated the efflux of citrate, and the strict specificity of this MATE was indicated that it did not mediate malate secretion. HvAACT1 was presumed to be localized to the plasma membrane, and transgenic tobacco expressing HvAACTl also showed higher citrate secretion in the presence of aluminum and exhibited higher tolerance to aluminum, but the citrate secretion was not altered in the absence of aluminum despite the constitutive promoter in the heterologous host (Furukawa et al. 2007). A homologous gene that is involved in aluminum resistance has also been reported recently in sorghum (Magalhaes et al. 2007), while in wheat another type of transporter molecule that did not belong to the MATE family was identified, which mediated malate secretion from the root to generate aluminum tolerance.

Table 1 Properties of plant MATE-type transporters

\begin{tabular}{|c|c|c|c|c|c|c|}
\hline Plant & Name & $\begin{array}{l}\text { Driving } \\
\text { force }\end{array}$ & $\begin{array}{l}\text { Subcellular } \\
\text { localization }\end{array}$ & Tissue & Substrate & $\begin{array}{l}\text { Proposed physiological } \\
\text { function }\end{array}$ \\
\hline \multirow[t]{5}{*}{ Arabidopsis } & $A L F 5$ & N.D. & N.D. & Root (epidermis, cortex) & (TMA, PVP) & $\begin{array}{l}\text { Protection of the root } \\
\text { from toxic compounds }\end{array}$ \\
\hline & DTX1 & $\mathrm{H}^{+}$ & $\mathrm{PM}$ & Flower, leaf, stem, root & $\begin{array}{l}\text { (Norfloxacin, EtBr, } \\
\text { berberine, } \\
\text { heavy metals) }\end{array}$ & $\begin{array}{l}\text { Efflux of endogenous } \\
\text { metabolites and } \\
\text { xenobiotics }\end{array}$ \\
\hline & EDS5 & N.D. & N.D. & N.D. & N.D. & $\begin{array}{l}\text { Salicylic acid- } \\
\text { dependent signaling } \\
\text { cascade for disease } \\
\text { resistance }\end{array}$ \\
\hline & FRD3 & N.D. & N.D. & $\begin{array}{l}\text { Root (pericycle, } \\
\text { vascular cylinder) }\end{array}$ & Citrate & $\begin{array}{l}\text { Efflux of citrate into the } \\
\text { root vasculature for } \\
\text { iron translocation }\end{array}$ \\
\hline & $T T 12$ & $\mathrm{H}^{+}$ & Vac & Seed coat endothelium & Flavonoids & $\begin{array}{l}\text { Vacuolar flavonoid } / \mathrm{H}^{+} \\
\text {antiporter in the seed } \\
\text { coat }\end{array}$ \\
\hline Tomato & MTP77 & N.D. & N.D. & N.D. & N.D. & $\begin{array}{l}\text { Vacuolar transporter of } \\
\text { anthocyanins (similar } \\
\text { to TT12) }\end{array}$ \\
\hline Lupin & LaMATE & N.D. & $\mathrm{PM}$ & Root & N.D. & N.D. \\
\hline \multirow[t]{2}{*}{ Barley } & HvMATE & N.D. & N.D. & N.D. & (Citrate) & Aluminum tolerance \\
\hline & $H v A A C T 1$ & N.D. & PM & Root, shoot & Citrate & $\begin{array}{l}\text { Al-activated efflux } \\
\text { carrier of citrate, } \\
\text { aluminum tolerance }\end{array}$ \\
\hline Sorghum & SbMATE & N.D. & PM & Root & (Citrate) & $\begin{array}{l}\text { Al-activated efflux } \\
\text { carrier of citrate, } \\
\text { aluminum tolerance }\end{array}$ \\
\hline
\end{tabular}

N.D.-Not determined; PM-Plasma membrane; Vac-Vacuole; TMA-Tetramethylammonium; PVP-Polyvinylpyrrolidone; EtBr-Ethidium bromide 


\section{Conclusion}

Secondary metabolites are transported both intercellularly and intracellularly in plants to be stored in preferential organelles or organs after biosynthesis. Recent progresses in plant molecular biology and biochemistry as well as informatics providing the information on genome sequences and ESTs (expressed sequence tags) enabled us to identify various secondary transporter molecules involved in the uptake and efflux of plant secondary metabolites. Among many divergent secondary transporters, MATE family members are of particular importance as they have a wide range of transport functions including anthocyanin uptake, iron translocation, and aluminum resistance (Fig. 4) (Table 1), and many other functions of MATE family members will be elucidated in near future. Contrary to its name and original understanding in prokaryotes, MATE transporters may not necessarily be multi-specific in plants as shown in AtTT12 and HvAACT1, which are specific for particular endogenous substrates. This resembles the situation of plant $\mathrm{ABC}$ transporters, in which no typical multidrug efflux pump has been identified so far. Considering the much higher number of these transporter proteins in plants than in bacteria and animals, MATE transporters as well as $\mathrm{ABC}$ transporters may play specific physiological functions by transporting a narrow-range of endogenous metabolites in planta.

Plant secondary metabolites are a large resource of natural medicines and exhibit various pharmacological and biological activities. Intensive metabolic engineerings targeting better production has been a recent trend in this field, and indeed many attempts have been carried out throughout the world. In these studies the importance of membrane transport of final products as well as their intermediates was highlighted, because biosynthetic pathways and transport activities are interconnected with each other, and both biosynthetic enzymes and transporters involved should be considered at the same time for effective metabolic engineering. As such transporters the direct involvement of proton gradient-dependent transporters has become more widely known. Better understanding of secondary transporters with their regulatory mechanisms by biosynthetic pathways will proved us with better strategies for metabolic engineering for commercial applications.
Acknowledgements Research fund: Grant-in-Aid for Scientific Research (No. 19039019 to K. Y.) from the Ministry of Education, Culture, Sports, Science, and Technology of Japan. We apologize to those authors whose work was not cited in the pursuit of brevity.

Open Access This article is distributed under the terms of the Creative Commons Attribution Noncommercial License which permits any noncommercial use, distribution, and reproduction in any medium, provided the original author(s) and source are credited.

\section{References}

Behnke K, Ehlting B, Teuber M, Bauerfeind M, Louis S, Hansch R, Polle A, Bohlmann J, Schnitzler JP (2007) Transgenic, non-isoprene emitting poplars don't like it hot. Plant J 51:485-499

Blom TJM, Sierra M, van Vliet TB, Franke-van Dijk MEI, de Koning P, van Iren F, Verpoorte R, Libbenga KR (1991) Uptake and accumulation of ajmalicine into isolated vacuoles of cultured cells of Catharanthus roseus (L.) G. Don. and its conversion into serpentine. Planta 183:170-177

Chandran D, Reinders A, Ward JM (2003) Substrate specificity of the Arabidopsis thaliana sucrose transporter AtSUC2. J Biol Chem 278:44320-44325

Croteau R, Kutchan TM, Lewis NG (2000) Natural products (secondary metabolites). American Society of Plant Physiologists, Maryland

Debeaujon I, Peeters AJ, Leon-Kloosterziel KM, Koornneef M (2001) The TRANSPARENT TESTA12 gene of Arabidopsis encodes a multidrug secondary transporter-like protein required for flavonoid sequestration in vacuoles of the seed coat endothelium. Plant Cell 13:853-871

Deus-Neumann B, Zenk MH (1984) A highly selective alkaloid uptake system in vacuoles of higher plants. Planta 162:250-260

Deus-Neumann B, Zenk MH (1986) Accumulation of alkaloids in plant vacuoles does not involve an ion-trap mechanism. Planta 167:44-53

Devic M, Guilleminot J, Debeaujon I, Bechtold N, Bensaude E, Koornneef M, Pelletier G, Delseny M (1999) The BANYULS gene encodes a DFR-like protein and is a marker of early seed coat development. Plant J 19:387-398

Diener AC, Gaxiola RA, Fink GR (2001) Arabidopsis ALF5, a multidrug efflux transporter gene family member, confers resistance to toxins. Plant Cell 13:1625-1638

Durrett TP, Gassmann W, Rogers EE (2007) The FRD3mediated efflux of citrate into the root vasculature is necessary for efficient iron translocation. Plant Physiol 144:197-205

Frangne N, Eggmann T, Koblischke C, Weissenbock G, Martinoia E, Klein M (2002) Flavone glucoside uptake into barley mesophyll and Arabidopsis cell culture vacuoles. Energization occurs by $\mathrm{H}(+)$-antiport and ATP-binding cassette-type mechanisms. Plant Physiol 128:726-733

Furukawa J, Yamaji N, Wang H, Mitani N, Murata Y, Sato K, Katsuhara M, Takeda K, Ma JF (2007) An aluminum- 
activated citrate transporter in barley. Plant Cell Physiol 48:1081-1091

Gaxiola RA, Palmgren MG, Schumacher K (2007) Plant proton pumps. FEBS Lett 581:2204-2214

Goodman CD, Casati P, Walbot V (2004) A multidrug resistance-associated protein involved in anthocyanin transport in Zea mays. Plant Cell 16:1812-1826

Goossens A, Hakkinen ST, Laakso I, Seppanen-Laakso T, Biondi S, De Sutter V, Lammertyn F, Nuutila AM, Soderlund $\mathrm{H}$, Zabeau $\mathrm{M}$, Inze D, Oksman-Caldentey KM (2003) A functional genomics approach toward the understanding of secondary metabolism in plant cells. Proc Natl Acad Sci USA 100:8595-8600

Green LS, Rogers EE (2004) FRD3 controls iron localization in Arabidopsis. Plant Physiol 136:2523-2531

Hashimoto T, Yamada Y (2003) New genes in alkaloid metabolism and transport. Curr Opin Biotechnol 14: 163-168

Hiasa M, Matsumoto T, Komatsu T, Moriyama Y (2006) Wide variety of locations for rodent MATE1, a transporter protein that mediates the final excretion step for toxic organic cations. Am J Physiol Cell Physiol 291:C678-C686

Iwasa K, Nanba H, Lee DU, Kang SI (1998) Structure-activity relationships of protoberberines having antimicrobial activity. Planta Med 64:748-751

Jasinski M, Stukkens Y, Degand H, Purnelle B, MarchandBrynaert J, Boutry M (2001) A plant plasma membrane ATP binding cassette-type transporter is involved in antifungal terpenoid secretion. Plant Cell 13:1095-1107

Klein M, Weissenbock G, Dufaud A, Gaillard C, Kreuz K, Martinoia E (1996) Different energization mechanisms drive the vacuolar uptake of a flavonoid glucoside and a herbicide glucoside. J Biol Chem 271:29666-29671

Kochian LV, Pineros MA, Hoekenga OA (2005) The physiology, genetics and molecular biology of plant aluminum resistance and toxicity. Plant Soil 274:175-195

Kojima S, Bohner A, von Wiren N (2006) Molecular mechanisms of urea transport in plants. J Membr Biol 212:83-91

Kojima S, Bohner A, Gassert B, Yuan L, von Wiren N (2007) AtDUR3 represents the major transporter for high-affinity urea transport across the plasma membrane of nitrogendeficient Arabidopsis roots. Plant J 52:30-40

Kunst L, Samuels AL (2003) Biosynthesis and secretion of plant cuticular wax. Prog Lipid Res 42:51-80

Lepiniec L, Debeaujon I, Routaboul JM, Baudry A, Pourcel L, Nesi N, Caboche M (2006) Genetics and biochemistry of seed flavonoids. Annu Rev Plant Biol 57:405-430

Li L, He Z, Pandey GK, Tsuchiya T, Luan S (2002) Functional cloning and characterization of a plant efflux carrier for multidrug and heavy metal detoxification. J Biol Chem 277:5360-5368

Liu LH, Ludewig U, Frommer WB, von Wiren N (2003) AtDUR3 encodes a new type of high-affinity urea/H+ symporter in Arabidopsis. Plant Cell 15:790-800

Loivamaki M, Gilmer F, Fischbach RJ, Sorgel C, Bachl A, Walter A, Schnitzler JP (2007) Arabidopsis, a model to study biological functions of isoprene emission? Plant Physiol 144:1066-1078

Ludwig A, Stolz J, Sauer N (2000) Plant sucrose-H+ symporters mediate the transport of vitamin $\mathrm{H}$. Plant $\mathrm{J}$ 24:503-509
Ma JF, Furukawa J (2003) Recent progress in the research of external Al detoxification in higher plants: a minireview. J Inorg Biochem 97:46-51

Ma JF, Ryan PR, Delhaize E (2001) Aluminium resistance in plants and the complexing role of organic acids. Trends Plant Sci 6:273-278

Magalhaes JV, Liu J, Guimarães CT, Lana UGP, Alves VMC, Wang Y-H, SchaVert RE, Hoekenga OA, ShaV JE, Piñeros MA, Klein PE, Coelho CM, Kochian LV (2007) A gene in the multidrug and toxic compound extrusion (MATE) family confers aluminum tolerance in sorghum. Nat Genet 39:1156-1161

Marinova K, Kleinschmidt K, Weissenbock G, Klein M (2007a) Flavonoid biosynthesis in barley primary leaves requires the presence of the vacuole and controls the activity of vacuolar flavonoid transport. Plant Physiol 144:432-444

Marinova K, Pourcel L, Weder B, Schwarz M, Barron D, Routaboul JM, Debeaujon I, Klein M (2007b) The arabidopsis MATE transporter TT12 acts as a vacuolar flavonoid/H+-antiporter active in proanthocyanidin-accumulating cells of the seed coat. Plant Cell 19:2023-2038

Marrs KA, Alfenito MR, Lloyd AM, Walbot V (1995) A glutathione S-transferase involved in vacuolar transfer encoded by the maize gene Bronze-2. Nature 375: 397-400

Martinoia E, Maeshima M, Neuhaus HE (2007) Vacuolar transporters and their essential role in plant metabolism. J Exp Bot 58:83-102

Masuda S, Terada T, Yonezawa A, Tanihara Y, Kishimoto K, Katsura T, Ogawa O, Inui K (2006) Identification and functional characterization of a new human kidney-specific H+/organic cation antiporter, kidney-specific multidrug and toxin extrusion 2. J Am Soc Nephrol $17: 2127-2135$

Mathews H, Clendennen SK, Caldwell CG, Liu XL, Connors K, Matheis N, Schuster DK, Menasco DJ, Wagoner W, Lightner J, Wagner DR (2003) Activation tagging in tomato identifies a transcriptional regulator of anthocyanin biosynthesis, modification, and transport. Plant Cell 15:1689-1703

Matile P (1984) Das toxische Kompartiment der Pflanzenzelle. Naturwissenschaften 71:18-24

McCaskill DG, Martin DL, Scott AI (1988) Characterization of alkaloid uptake by Catharanthus roseus (L.) G. Don protoplasts. Plant Physiol 87:402-408

Morita Y, Kodama K, Shiota S, Mine T, Kataoka A, Mizushima T, Tsuchiya T (1998) NorM, a putative multidrug efflux protein, of Vibrio parahaemolyticus and its homo$\log$ in Escherichia coli. Antimicrob Agents Chemother 42:1778-1782

Morita Y, Kataoka A, Shiota S, Mizushima T, Tsuchiya T (2000) NorM of vibrio parahaemolyticus is an $\mathrm{Na}(+)$ driven multidrug efflux pump. J Bacteriol 182:6694-6697

Nakagawa K, Konagai A, Fukui H, Tabata M (1984) Release and crystallization of berberine in the liquid medium of Thalictrum minus cell suspension cultures. Plant Cell Reports 3:254-257

Nawrath C, Heck S, Parinthawong N, Metraux JP (2002) EDS5, an essential component of salicylic acid-dependent signaling for disease resistance in Arabidopsis, is a 
member of the MATE transporter family. Plant Cell 14:275-286

Neumann D, Krauss G, Hieke M, Groger D (1983) Indole alkaloid formation and storage in cell suspension cultures of Catharanthus roseus. Planta Med 48:20-23

Niinemets U, Loreto F, Reichstein M (2004) Physiological and physicochemical controls on foliar volatile organic compound emissions. Trends Plant Sci 9:180-186

Omote H, Hiasa M, Matsumoto T, Otsuka M, Moriyama Y (2006) The MATE proteins as fundamental transporters of metabolic and xenobiotic organic cations. Trends Pharmacol Sci 27:587-593

Otani M, Shitan N, Sakai K, Martinoia E, Sato F, Yazaki K (2005) Characterization of vacuolar transport of the endogenous alkaloid berberine in Coptis japonica. Plant Physiol 138:1939-1946

Otsuka M, Matsumoto T, Morimoto R, Arioka S, Omote H, Moriyama Y (2005a) A human transporter protein that mediates the final excretion step for toxic organic cations. Proc Natl Acad Sci USA 102:17923-17928

Otsuka M, Yasuda M, Morita Y, Otsuka C, Tsuchiya T, Omote $\mathrm{H}$, Moriyama $\mathrm{Y}$ (2005b) Identification of essential amino acid residues of the NorM Na+/multidrug antiporter in Vibrio parahaemolyticus. J Bacteriol 187:1552-1558

Rea PA (2007) Plant ATP-binding cassette transporters. Annu Rev Plant Biol 58:347-375

Reuber S, Bornman J, Weissenböck G (1996) A flavonoid mutant of barley (Hordeum vulgare L.) exhibits increased sensitivity to UV-B radiation in the primary leaf. Plant Cell Environ 19:593-601

Rogers EE, Guerinot ML (2002) FRD3, a member of the multidrug and toxin efflux family, controls iron deficiency responses in Arabidopsis. Plant Cell 14:1787-1799

Sakai K, Shitan N, Sato F, Ueda K, Yazaki K (2002) Characterization of berberine transport into Coptis japonica cells and the involvement of ABC protein. J Exp Bot 53:1879-1886

Sasaki K, Saito T, Lamsa M, Oksman-Caldentey KM, Suzuki M, Ohyama K, Muranaka T, Ohara K, Yazaki K (2007) Plants utilize isoprene emission as a thermotolerance mechanism. Plant Cell Physiol 48:1254-1262

Sato H, Kobayashi Y, Fukui H, Tabata M (1990) Specific differences in tolerance to exogenous berberine among plant cell cultures. Plant Cell Rep 9:133-136
Sato H, Tanaka S, Tabata M (1993) Kinetics of alkaloid uptake by cultured cells of Coptis japonica. Phytochemistry 34:697-701

Sato F, Takeshita N, Fujiwara H, Katagiri Y, Huan L, Yamada Y (1994) Characterization of Coptis japonica cells with different alkaloid productivities. Plant Cell Tissue Organ Cult 38:249-256

Shitan N, Bazin I, Dan K, Obata K, Kigawa K, Ueda K, Sato F, Forestier C, Yazaki K (2003) Involvement of CjMDR1, a plant multidrug-resistance-type ATP-binding cassette protein, in alkaloid transport in Coptis japonica. Proc Natl Acad Sci USA 100:751-756

Smit G, Puvanesarajah V, Carlson RW, Barbour WM, Stacey G (1992) Bradyrhizobium japonicum nodD1 can be specifically induced by soybean flavonoids that do not induce the nodYABCSUIJ operon. J Biol Chem 267: 310-318

Sugiyama A, Shitan N, Yazaki K (2007) Involvement of a soybean ATP-binding cassette-type transporter in the secretion of genistein, a signal flavonoid in legume-rhizobium symbiosis. Plant Physiol 144:2000-2008

Terasaka K, Sakai K, Sato F, Yamamoto H, Yazaki K (2003) Thalictrum minus cell cultures and ABC-like transporter. Phytochemistry 62:483-489

Uhde-Stone C, Liu J, Zinn KE, Allan DL, Vance CP (2005) Transgenic proteoid roots of white lupin: a vehicle for characterizing and silencing root genes involved in adaptation to $\mathrm{P}$ stress. Plant J 44:840-853

Wang J, Raman H, Zhou M, Ryan PR, Delhaize E, Hebb DM, Coombes N, Mendham N (2007) High-resolution mapping of the Alp locus and identification of a candidate gene HvMATE controlling aluminium tolerance in barley (Hordeum vulgare L.). Theor Appl Genet 115: 265-276

Yamamoto K, Takase H, Abe K, Saito Y, Suzuki A (1993) Pharmacological studies on antidiarrheal effects of a preparation containing berberine and geranii herba. Nippon Yakurigaku Zasshi 101:169-175

Yazaki K (2005) Transporters of secondary metabolites. Curr Opin Plant Biol 8:301-307

Yazaki K (2006) ABC transporters involved in the transport of plant secondary metabolites. FEBS Lett 580:1183-1191 